\title{
Closing the Loop: An Evaluation of Student-Led Module Feedback at one UK Higher Education Institution
}

\author{
*Cécile Tschirhart, The CASS, London Metropolitan University, London, UK \\ Simon Pratt-Adams, Anglia Learning and Teaching and Faculty of Health, Education, \\ Medicine and Social Care, Anglia Ruskin University, Cambridge, UK
}

Contact: $\underline{\text { c.tschirhart@londonmet.ac.uk }}$

\section{ABSTRACT}

This article describes how a Student-Led Module Feedback (SLMF) scheme was initiated at one UK University to enhance staff-student relationships and to improve student outcomes. The scheme was developed by academics in partnership with the Students Union (SU) and students. The SLMF aimed to enhance the student experience at a granular level in "real time" during 30 week-long teaching modules. The article defines the SLMF within the research context of the Scholarship of Teaching and Learning and describes how the theme of student-staff partnership runs across the scheme, including during the project management and evaluation phases. It critically reflects on how the scheme has been instrumental in making inroads to improving the experience of students and staff across the university. It analyses the way in which the SLMF is being used by staff and students to co-create action plans to initiate pedagogical changes and thus close the loop of the feedback cycle.

\section{KEYWORDS}

survey, student experience, student-staff partnership, learning and teaching enhancement, staff experience

In response to attempts by the UK government to define universities as service providers and students as consumers with rights (Department for Business, Innovation and Skills, 2011, p. 37), institutions have developed a wide range of Students-as-Partners (SaP) initiatives. Healey, Flint, and Harrington (2014) describe partnership as "a relationship in which all participants are actively engaged in and stand to gain from the process of learning and working together" (p. 7).

Cook-Sather, Bovill, and Felten (2014) acknowledge that partnership can take different forms and scales, illustrating the flexibility of partnership models in different contexts to reflect the aims, commitments, and needs of an individual institution.

The Programme for the Improvement of Student Outcomes (PISO) was introduced at one UK University in 2015 to enhance the student experience and student outcomes (as 
measured by retention, progression, attainment, and reported metrics). The PISO board, supported by the university academic board, identified the Student-Led Module Feedback scheme as a key project. The SLMF process incorporated a student survey that aimed to enhance the student experience in "real time" during the teaching delivery of 30 week-long modules. A pilot was established in partnership with the Students' Union (SU) to build a trusting community of learning between staff and students. Ramsden (2008) highlights the importance of student involvement in quality processes based on the idea of building learning communities so that they can take ownership of quality enhancement and engage with staff in dialogue about improving teaching delivery.

The pilot phase, designed and devised with students and staff, involved surveying 3,157 level- 6 students (levels 3, 4, 5, and 6 correspond to years 0, 1, 2, and 3 of undergraduate study) at the university. It aimed at evaluating the scheme's impact on the learning experience, reviewing the process, and improving the delivery of the scheme. Recommendations to improve further iterations presented at the academic board were approved.

On the surface, the SLMF is a traditional student-experience survey. However, through its innovative implementation process, based on dialogue between staff and students and co-action planning, its objectives are clearly focused on initiating cultural change in learning, teaching, and assessment, thus echoing the thoughts of Healey et al. (2014) that "partnership is essentially a process of engagement, not a product. It is a way of doing things, rather than an outcome in itself. All partnership is student engagement, but not all student engagement is partnership" (p. 7).

To achieve a cultural change in student-staff relations across the institution, a working group consisting of academic staff and students identified objectives that would lead to improvements in the learning experience. It was critical that both staff and students had ownership of the process and could see benefits from that partnership. The definition of roles in the process of the SLMF was a key step in ensuring the success of such an initiative. Dunne and Zandstra (2011), for example, offer a model for students as change agents in the learning and teaching context. They recognise that student engagement can take many forms, including students as evaluators of their experience; students as participants in the decision-making process; students as partners, co-creators, and experts; and, finally, students as agents for change. The SMLF's objectives included engaging all the actors in the teaching and learning process through reflection, dialogue, and change. The scheme's ultimate aim was to sow the seeds for an equal and meaningful partnership between academic staff and students.

It was significant that the senior leadership team of the university fully supported the SLMF and the former Vice-Chancellor recognised the impact of the initiative: "We gave students significant leadership responsibilities in each of the PISO programme strands, and we invited students to run our SLMF (Student-Led Module Feedback), which became a significant factor driving course improvements" (Raftery, 2018).

Some long-established ways of monitoring quality enhancement can lead to staff's reluctance to engage in change. Reviewing past evaluation data, rather than actively engaging with and listening to the views of current students, is a common occurrence in the UK quality enhancement cycle. The SLMF was developed specifically to address this issue, to challenge existing practices, and to enable change for students and staff. According to Healey et al. (2014), when an institution goes beyond collating data on the student voice and engages students in pedagogic consultancy, it sees significant benefits for both staff and 
students. There is the potential for institutional transformation and change, but as CookSather et al. (2014) note, "while the benefits are real, neither partnership nor programme level work is a panacea" (p. 89).

\section{BACKGROUND}

Different types of student partnerships can reflect the aims, commitments, and needs of a particular institution. The institution under discussion here is one of the most socially inclusive universities in the UK, where two thirds of students come from the top two quintiles of Indices of Multiple Deprivation which is the official measure of relative deprivation for small areas in England. Nearly two thirds of students, or $60.1 \%$, are from a Black or Minority Ethnic (BME) background, $51.1 \%$ are aged 25 or older, $12.9 \%$ have a known disability, and $97.2 \%$ are from state-funded schools.

Historically, student satisfaction at the university has been surveyed at the end of a module, and changes have been put in place for subsequent cohorts. There were a number of issues with this process. Students who made suggestions for changes never benefitted from the outcomes, incoming students were not aware that changes had been made, and changes identified by one cohort were not necessarily applicable to the next. Crucially, there was no real-time dialogue between staff and students about the learning and teaching quality. Furthermore, only staff saw individual comments from students, and only they could report on these comments. In essence, there was no authentic partnership between staff and students in co-owning and co-creating plans and aspirations for module change.

\section{LITERATURE REVIEW}

Much has been published about the many ways to engage students as partners (Dunne \& Owen, 2013; Cook-Sather et al., 2014; Healey et al., 2014), and we refer to theoretical and conceptual models that have proven successful across the sector and that best fit with the SLMF. The 2011 white paper, Higher Education: Students at the Heart of the System, states that the higher education (HE) sector should be more accountable to students. The white paper created an opportunity for providers to empower students to be "equally invested in the common goal of learning" (Cook-Sather et al., 2014; p. 11). Providers were also encouraged to make students feel more at ease at university through "supportive peer relations, meaningful interaction between staff and students, developing knowledge, confidence and successful HE learners, a HE experience relevant to students' interests and future goals" (Thomas, 2012, p. 7).

In their report, Engagement Through Partnership: Students as Partners in Learning and Teaching in Higher Education, Healey et al. (2014) present a pedagogical case for partnership and propose a conceptual model that maps the different levels of partnership. Cook-Sather et al. (2014) propose that there are three foundations of any student-staff partnership, namely respect, reciprocity, and responsibility, which "includes making collaborative and transparent decisions about changing our practices in some instances and not in others" (p. 8).

Challenging the dominant model of student as consumer in an age of the commodification of higher education, McCulloch (2009) states that rather than the terms "client" or "consumer," "co-producer" is a more appropriate term for students. The studentas-consumer metaphor distances the student from the educational process, encourages passivity, does not encourage deep learning, and implies a level of knowledge and information that the student might not have. 
Dunne and Owen (2013) acknowledge that there are many definitions of student engagement that lead to success. Engagement can include student participation, teamwork, and community as well as partnership, co-creation, and collaboration. Engagement can also relate to different aspects of the curriculum involving teaching, learning, assessment, and the engagement of students in these processes. Thomas (2012) suggests that to achieve successful student engagement, "activities should proactively seek to engage students and develop their capacity to do so, rather than waiting for a crisis to occur, or the more confident students to take up opportunities" (p. 9).

Student engagement also relates to other areas such as student satisfaction, student experience, and the student voice. The UK government's white paper, Higher Education: Success as a Knowledge Economy, advocates a focus on student feedback, stating: "we consider the publication and effective use of student surveys and other evaluations to be at the heart of a continuous process of improving teacher quality" (Department for Business, Innovation \& Skills, 2011, p. 34).

Surveys, however, tend to focus on student satisfaction. While the student voice in surveys is both important and powerful for universities to understand what they need to develop and change, it is not the same as students taking the initiative for institutional or individual progress. In fact, in such circumstances it is not the student voice itself that is heard but rather other interpretations of what the students are saying. Van der Velden (2013) discusses staff perception of student engagement against a policy background of strengthening the student voice, which is an area that is lacking in the literature. The findings indicate a staff preference for collegial engagement, but there are obstacles to achieving this. Van der Velden (2013) suggests a different conceptual paradigm that involves both educational as well as organisational aspects of the learning experience, which are referred to as transactional and transformational aspects of the education process. Referring to feedback on assessment, for example, Lizzio and Wilson (2009) explain that "the transformational aspects remain firmly embedded within the academic realm such as the classroom or the tutorial where staff and students continue to engage in academic matters without the interference of a potentially adversarial climate of differing transactional interests" (p. 89).

Fluckiger et al. (2010) describe how to engage students as partners by providing timely formative feedback so that students can revise their work and improve their learning. They do this by providing more frequent formative feedback, including engaging students in peer feedback using quizzes, midterm student conferencing, shared revision of studentgenerated questions, and collaborative assignment blogs.

Cook-Sather et al. (2014) define the student-staff partnership as a collaborative and reciprocal process which allows everybody to add value to the curriculum, make decisions about pedagogy, and evaluate and analyse initiatives. This supports the view that partnership in such projects must be continually renegotiated.

In their systematic literature review, Mercer-Mapstone et al. (2017) propose nine implications to guide future research and practices when working with students as partners, including that of scaling up such initiatives with a view to create more sustainable practices. They, too, report that Students as Partners is "as complex, nuanced, and multifaceted as the educational institutions within which partnerships unfold" (19).

The SLMF aims at encouraging staff and students to work together, engaging the students as partners in enhancing the quality of their module. This approach is not dissimilar to the student-led action research initiative engaging "students as change agents" at 
University of Exeter, which brought students and staff together to improve experiences of HE (Dunne \& Zandstra, 2011). Ratcliffe and Dimmock (2013) discuss the student engagement strategy at the University of Exeter, which focused on student initiatives and activities that occur outside the classroom. They argue that "student motivation to engage rests on a combination of cultural expectation, temptation, self-interest, and altruism" ( $p$. 59).

Ratcliffe and Dimmock (2013) also note that "involving students with the running, organisation, and development of their own university empowers and stretches them. It offers a valuable experience and supports the development of a more active skill set that will allow them to succeed as graduates" (pp. 74-5).

\section{DESCRIPTION OF THE INITIATIVE}

The objectives of the SMLF included improving the student experience and university metrics and also extending a sense of pride among tutors and students. The institution's Student Academic Representatives (StARs) identified the project as a way to increase their visibility and to improve their skills in making representations to staff in committees and reports.

Early discussions identified that students and staff sometimes felt excluded from decisions and implementation processes due to speed of change, lack of ownership, and weak communication. Therefore, the nominated project lead (one of the authors of this paper) consulted with key stakeholders to identify the best structure for the SLMF to address these concerns. For the 2015/16 pilot phase, a brainstorming session took place between staff and student representatives (StARs) about improving the feedback loop and the student voice. Staff and students shared their thoughts on issues to understand where they stemmed from, considered who may be suitable facilitators, and attempted to identify what could be done practically to move the project forward.

A broad, real-time feedback scheme was consequently agreed upon with the aim of achieving key objectives. These included improving the learning experience through an ongoing dialogue between students and staff in order to create a transparent and open feedback loop, which would increase confidence in initiating change. As Cook-Sather et al. (2014) state,

students have essential perspectives, that when brought into dialogue with teachers' perspectives, can raise awareness, deepen engagement, improve teaching and learning for all involved, and foster a culture on campus that embraces more open communication about, and shared responsibility for education. (p. xiii)

A wide range of people were invited to join the initial meeting to discuss membership and roles. This led to all parties identifying their strengths, capacities, and priorities. It was agreed that the project management would be shared among the following parties: the project lead, the Student Union (SU), a representative from each academic school/area and one from internal communications, and a quality office representative and software administrator. The group decided to use Google Drive, a tool accessible anywhere, anytime, which would allow all participants to contribute. Editors had access to a live document, which included a Gantt chart with live updates on the progress of the project, a communication plan with pre-drafted emails, a reflective space entitled "Ideas" to record reflections and thoughts as the project evolved, and a "Questions and Answers" tab. 
Members were alerted to changes through the "Update" feature on Google Drive. This allowed all participants to own the way in which the project was run, to record concerns, to make useful suggestions and acted as a repository for future iterations of the scheme. More importantly, the platform allowed members to capture the entirety and complexity of the project in one place and to access it live and on the go.

\section{Approach to the study and implementation}

Cook-Sather et al. (2014) recommend that all partnership projects need to start small because "there will be surprises, good and bad, and because collaboration is more complex and demanding than solitary endeavours" (p. 139).

Following the pilot, the project team agreed that a survey would be used to gather information from a large number of students. A questionnaire (designed by staff and students) was used to measure five aspects of student life: student satisfaction, teaching quality, module organisation, sense of belonging, and quality and promptness of feedback. The SMLF group decided that the formulation of the statements should replicate the UK National Student Survey (NSS) questions so that respondents would become familiar with them. The project team used EvaSys, a survey automation software that allowed dual delivery (i.e., paper and online surveys). The survey was anonymous and included five quantitative questions and two open-ended questions. Module coding enabled identification of students by level of study and course.

Students were requested to respond to one of five statements using a Likert scale ranging from strongly disagree to strongly agree. The five statements were:

1. Staff are good at explaining and making the subject interesting

2. The module is well organised and I am informed about practical changes

3. I feel part of a community of staff and students

4. I have received good individual support and feedback about my progress in a timely manner

5. I am satisfied with my module so far

Respondents were asked two open-ended questions: "name three things you enjoyed about the module" and "name three things that could be improved." The use of EvaSys facilitated the implementation of the large-scale survey and offered the possibility of integration into a Virtual Learning Environment (VLE).

All 8,264 undergraduate students in the university were invited to respond to the survey across the four levels of undergraduate study. Each student was sent one questionnaire per module that they studied. The maximum number of questionnaires sent was six for a full-time student. A total of 31,592 questionnaires were issued.

The SLMF was advertised to students and staff through university internal communications including social media, posters, and computer monitors before the questionnaires were emailed to students. StARs attended lectures and seminars to present the scheme among their subject cohorts during the week the questionnaires were distributed. The StARs emphasised the benefits of the dialogue that would take place between staff and students and encouraged students to be constructive and honest in their comments. The StARs were supported and briefed by the SU in order to ensure consistency of message and approach.

\section{Implementation}

Once the survey period was closed, the EvaSys administrator programmed a number of data reports, as agreed to by the project group. The quantitative reports and the 
qualitative comments were emailed to module leaders, StARs, and SMLF leads in each school/area in Week 9 of a 30-week long teaching period. This was followed by a conversation between staff and students involved in the SMLF in Week 10 where both parties agreed on an action plan together (see Figure 1, below). The action plans were made available to all via the university VLE. Finally, the feedback loop was closed when staff and students discussed the progress of the action plans in Weeks 12 and 13, still in real time, within the lifetime of the module. (See Figure 2, below).

Figure 1. SMLF module timeline

Teaching

Weeks 1-7
Teaching

Weeks 13-30

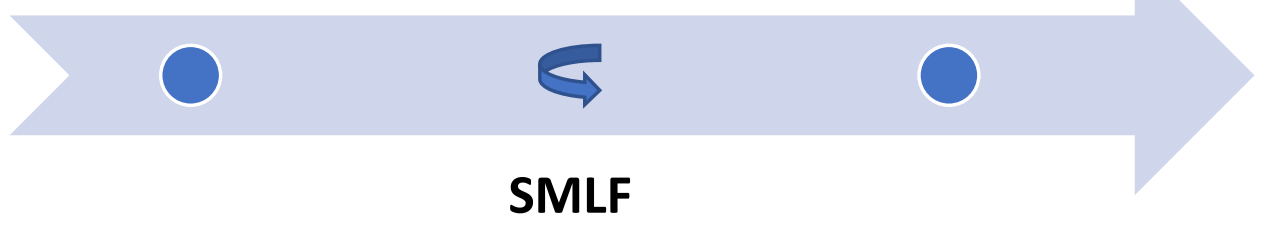

"closing the

loop"

Figure 2. SMLF timeline loop

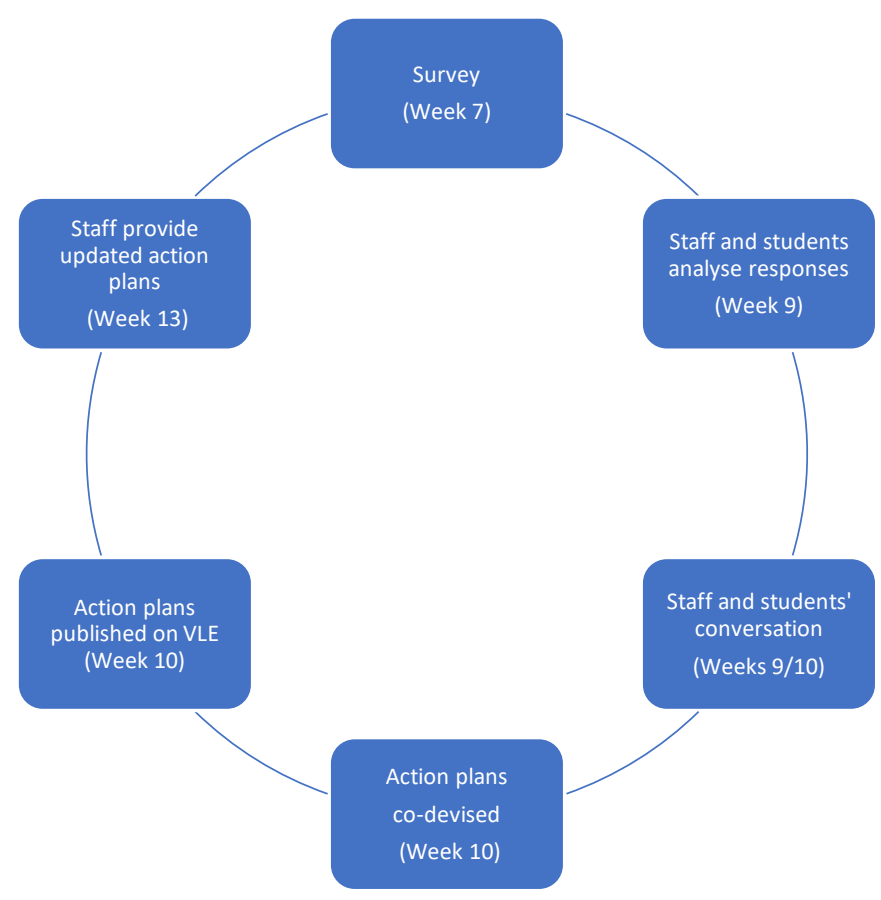

The project team produced guidelines on how to conduct the conversation between staff and students. This document was key in ensuring that the dialogue between staff and students was more important than the statistics or isolated comments. 
Of the 31,592 online questionnaires issued, 7,154 were completed by students in a period of two weeks, resulting in a $23 \%$ response rate. EvaSys allowed the administrator to programme reminders to non-respondents. In total, respondents were sent two reminders during the two-week period. The individual module survey reports, produced by the EvaSys, were emailed by the administrator to the teaching staff and StARs in Week 9. As agreed by the group, and in line with the NSS practice, the administrator removed all names of staff in the qualitative part of the reports.

In total, students provided over 20,000 free-text comments across the 794 modules. These were coded using a system of discourse analysis looking for similar words and phrases identified by the SMLF school/area representative to identify issues at a strategic level. To increase ownership of the scheme, staff and students were encouraged (through the guidelines) to challenge or embrace the results and to agree on what was relevant to discuss or not for their action plan.

The qualitative and quantitative results of the survey were discussed at the module level to initiate a conversation between staff and students and were translated into action plans. The project team collaboratively produced a guide for staff to initiate and manage the conversation and to co-produce a plan with students. The guide suggested a list of steps to engage in the conversation about the survey results, including how to respond to statistical data and how to value all comments made. The guide also provided examples of effective communication tools in order to promote meaningful engagement through active listening. There were also sample action plans cross-referencing common pedagogical concerns.

\section{Action plans}

The two qualitative questions were included primarily to engage staff and students in a live conversation. The action plans, collected in a shared Google document, were created after the dialogue between staff and students and were varied in their presentation and content (see Table 1 for examples of action plans).

\section{Table 1. Examples of action plans}

\section{Action Plan: Example 1}

- Ensure that seminar rooms are warmer

- Ensure each seminar group has parity of experience (recognising that staff have an individual teaching style!) (e.g., too much reading or group work in sessions to support the individual needs of each group)

- Each seminar tutor to discuss with the group what would work best for them (e.g., peer feedback, group work, readings during sessions, and so on)

\section{Action Plan: Example 2}

- The lecturers guarantee to leave a break of sufficient length when both the lecture and the tutorial take place in the same room

- Additional reading material will be provided to supplement the lecture notes

- Students to arrive on time

- A mock exam to be carried out after the first semester material and another one to cover the second semester material will be prepared

- More past exam papers will be published on the VLE as a preparation for the exam

While the majority were focused and solution-oriented, a very small minority were drafted in a defensive style, possibly indicating that students may not have taken an equal role in the drafting of the action plans. 


\section{DISCUSSION}

The scheme's outcomes and the action plans were reported to the academic board. It was noted that the themes discussed during the staff-student conversations and the points in the co-created action plans were similar to the themes collected through the National Student Survey at the institution over the years. This highlighted that one of the benefits of the scheme (i.e., being able to identify successes and to address areas of improvement on a course two months before the National Student Survey started) was achieved.

Feeling part of a community of staff and students is challenging for an inner city, noncampus university, where many students are local and live in the family home. It is, however, a crucial ingredient in the recipe for a positive student experience. The co-created action plans made some useful suggestions to encourage a sense of community amongst students such as increased induction activities. This information has been used by academic leads to develop, amongst other initiatives, a "transition to HE" online interactive package of activities to reinforce the feeling of belonging.

The schools/areas reported a number of useful trends which were identified in the action plans, the most resounding one being that students have a clear understanding of what is needed to improve their experience and are offering realistic solutions. Students are also clearly aware of their rights and educational needs. This could be partly due to the attention paid to metrics in early compulsory education which has led staff to "train" pupils/students from the outset to set their own objectives and goals, to conduct selfevaluations, and to identify the support and tools they need to pass examinations they undertake. In addition, the introduction of student fees to the HE sector could also explain the large number of comments related to lack of feedback and lack of preparation for exams.

\section{Impact of the SLMF on the teaching and learning experience}

To measure the impact of the SLMF, a questionnaire was sent to staff involved in the scheme. Its purpose was to evaluate the effectiveness of the scheme, and to solicit staff suggestions for improving it.

\section{Methods and design}

The staff evaluation used quantitative and qualitative methods. A questionnaire (designed by one of the authors of this paper) was used to measure the success and impact of the scheme on teaching and learning. There were seven questions and four open-ended questions. This paper reports an initial summary of the findings of the staff survey, which will be the subject of a future study. The survey was conducted using Google Forms and was sent to 232 module leaders who completed at least one SMLF action plan with their students. A total of 101 module leaders responded to the survey, equating to a $44 \%$ participation rate. In addition, there were just under 200 free-text comments. Staff were asked seven questions about promotion of the survey by the StARs and about student involvement in devising the action plans. They were invited to respond to free-text questions, in which they were encouraged to reflect on their teaching practice, their relationship with students, and the extent to which the SLMF enhanced student engagement in their modules.

\section{Analysis and discussion}

Google Forms created simple graphs to illustrate the yes/no questions and collated 
the free-text comments in sections. These were then analysed through a coding system using simple discourse analysis, which identified the main themes.

Staff reported that StARs attended $53 \%$ of lectures to promote the scheme, which demonstrated the impact and engagement of the SU in the scheme. Another indication of their commitment was providing training for StARs and organising the classroom visits. StARs were also involved in advertising the scheme to their peers via emails, social events, and social media.

The SMLF focused on encouraging students and staff working in partnership to enhance the teaching and learning experience and were thus "equally invested in the common goal of learning" (Cook-Sather et al., 2014, p. 11)

Sixty-three percent of staff indicated that students were actively involved in devising the action plans, and $59 \%$ of staff recognised that the action plans will have an impact on their future practice. Staff welcomed student suggestions; for example, to reduce the length of presentations, to increase task-based learning, to review the workload of assessment, to edit and reorganise the content of the VLE, to be more aware of the diverse needs of students, and to spend time giving individual feedback. Seventy-seven percent of staff stated that the scheme guidelines were helpful. Forty-three percent reported that they had learned something new about their teaching practice. When staff were probed about what they had learned about their teaching practice, the answers included implementing new ideas for improving feedback to students, reflecting on their teaching, improving communication between staff teams, working closer with students, and improving content of the VLE. Thirty-seven percent of staff thought that the scheme had a positive impact on their own relationship with their students. Another $37 \%$ were unsure, while $27 \%$ stated that the scheme did not have a positive impact. In this latter case, a small number of staff questioned the representativeness of the data in relation to low participation, while others felt challenged by the student voice.

The SLMF is a major cultural shift, and it will take time for some to accept it as a valid conduit for the student voice and as a platform to challenge notions of power as opposed to notions of partnership. As Cook-Sather et al. (2014) confirm, some staff may be uncomfortable with the changes in power relations that a more collaborative approach requires and will not willingly embrace a partnership model.

There are many reasons why students do or do not engage with their studies, and this scheme was one of the interventions put in place to promote student engagement. The findings indicated that $39 \%$ of staff thought that the scheme had enhanced student engagement with their module, and it was perceived as being an effective mechanism for students to give feedback and as an opportunity for staff to reflect on teaching practice and see immediate changes in the module. Some staff said that the anonymity of the SLMF enabled the "quieter voices" to be heard, and others felt that the scheme promoted a positive impression of the university by allowing students to identify strengths and by encouraging feedback. Staff said that the scheme facilitated meaningful interaction and dialogue between staff and students.

A number of suggestions for future improvements to the SMLF were made. While current student participation was positive, it was felt that we needed to consider ways in which participation could be increased. Finally, a very small minority of staff reported feeling "humiliated" by the outcomes and stated that, rather than enhancing the staffstudent relationships, the scheme had encouraged students to complain and be critical. Allin (2014) acknowledges that to forge successful partnerships with students, we need to 
critically reflect on the power relations that exist between staff and students, and we need to consciously empower students. Power sharing can be uncomfortable for some staff, both in principle and in learning and teaching practice, and this has been made more challenging in the current HE sector where the student voice is becoming louder. This discomfort is an inevitable consequence of the shift in power relations, and it is hoped that those feelings will fade as the scheme becomes more established. In their work, Healey and Healey (2018) argue that Student-as-Partners practices "involve a radical rethink of the power relationships between staff and students which encourages them to co-create knowledge, co-design the curriculum, and learn together" (p. 6).

\section{Implications of the SLMF for partnerships}

Student engagement with course evaluation and feedback can support the development of a more positive learning environment, the sharing of good practice, and students being active participants in their own learning, rather than being passive recipients. The SLMF offers a new conceptual model for working in partnership with students through course feedback. The scheme can create a sense of belonging among students through the development of partnership learning communities. An initiative such as the SLMF is also a way of engaging higher numbers of students in partnership work than is usual in the UK higher education sector. Furthermore, it is an approach that offers a whole-system model of partnership that can contribute ways of developing institutional policy in the area of quality enhancement.

The project offers an inter-disciplinary model that may guide and support enhanced and improved practice. This enables the development of a specific ethos for institutional partnerships, resulting from critical reflection of the process, such as the exploration of power relationships, issues of inclusivity and university structures through consideration of shared values, behaviours and attitudes. By encouraging students and staff to have open discussions about their experience in real time, the SLMF is a cultural shift in the institution because, for the first time, it has allowed students and staff to acknowledge each other's feelings and behaviours for the common purpose of enhancing the learning experience. Curran (2017) and Felten (2017) both highlight the importance and the role of emotions in Students-as-Partners projects. Curran (2017) argues that recognising how staff and students are feeling can act as a catalyst for change in thinking and behaviours.

Such an approach reinforces that "partnership is essentially a process of engagement, not a product" (Healey et al., 2014, p. 7). This process approach provides the mechanism for institutions to identify tensions and challenges that can emerge from the development of partnerships and can offer some approaches to address these and enable change to take place.

\section{CONCLUSION}

The few challenges encountered and reported, such as the tight timelines of the project, poor engagement from StARs in some courses, and a small minority of staff challenged by the openness of the scheme, did not overshadow the successes of the SLMF as a well-designed and co-managed project. It offered a measurable, positive impact on the student experience and a transparent approach to enhancing learning and teaching. The SLMF is "the survey that wasn't a survey" Tschirhart (2017). It is a tool to engage students and staff together in a process of reflection, conversation, and construction. It is about building a mature, honest relationship together, with students having the confidence to 
praise where necessary and the skills to raise issues constructively. It is also about staff responding to critique in a positive and reflective way.

Now in its fourth iteration, the SLMF is an established partnership. Successes are still being celebrated, and, more importantly, lessons are still being learnt by the university community. One could argue that it is a positive sign as the scheme can be adapted to new settings. In a rapidly changing UK higher education context, agility is a key to sustainability.

The research was successfully reviewed according to the institution's research ethics committee guidelines and given approval.

\section{NOTE ON CONTRIBUTORS}

Cécile Tschirhart is Head of Student Experience at The CASS, School of Art, Architecture and Design, London Metropolitan University. She leads on several university-wide student experience projects, including enhancing the student voice. Her interests include student engagement, academic support, digital learning, and the Scholarship of Teaching and Learning. She is a Senior and National Teaching Fellow of the UK Higher Education Academy.

Simon Pratt-Adams is a researcher with substantial experience in the fields of pedagogic research and urban education. He also holds various leadership and management positions in university departments of education. He is currently Acting Director of the Centre for Innovation in Higher Education in Anglia Learning and Teaching, Principal Lecturer in Academic Development in the Faculty of Health, Education, Medicine and Social Care at Anglia Ruskin University, and Visiting Professor at the Shanghai Youth College of Management. He is a Principal Fellow of the Higher Education Academy.

\section{REFERENCES}

Allin, L. (2014). Collaboration between staff and students in the scholarship of teaching and learning: The potential and the problems. Teaching \& Learning Inquiry, 2(1), pp. 95102. https://doi.org/10.20343/teachlearninqu.2.1.95

Cook-Sather, A., Bovill, C., \& Felten, P. (2014). Engaging students as partners in learning and teaching: A guide for faculty. Jossey-Bass, San Francisco.

Curran, R. (2017). Students as partners-good for students, good for staff: A study on the impact of partnership working and how this translates to improved student-staff engagement. International Journal for Students as Partners, 1(2). https://doi.org/10.15173/ijsap.v1i2.3089

Department for Business, Innovation \& Skills. (2011). Higher education: Students at the heart of the system. Retrieved from https://www.gov.uk/government/consultations/higher-education-white-paperstudents-at-the-heart-of-the-system

Department for Business, Innovation \& Skills. (2016). Success as a knowledge economy: Teaching excellence, social mobility and student choice. Retrieved from https://www.gov.uk/government/publications/higher-education-success-as-aknowledge-economy-white-paper 
Dunne, E., \& Owen, D. (2013). The student engagement handbook. Bingley: Emerald Group Publishing.

Dunne, E., \& Zandstra, R. (2011). Students as change agents: New ways of engaging with learning and teaching in higher education. York: ESCalate, HEA Subject Centre for Education.

Felten, P. (2017). Emotion and partnerships. International Journal for Students as Partners, 1(2). https://doi.org/10.15173/ijsap.v1i2.3070

Fluckiger, J., Tixier y Vigil, Y., Pasco, R., \& Danielson, K. (2010). Formative feedback: Involving students as partners in assessment to enhance learning. College Teaching, 58(4), pp. 136-140. https://doi.org/10.1080/87567555.2010.484031

Healey, M., \& Healey, R.L. (2018). "It depends": Exploring the context-dependent nature of 10 students as partners' practices and policies. International Journal for Students as Partners, 2(1). https://doi.org/10.15173/ijsap.v2i1.3472

Healey, M., Flint, A., \& Harrington, K. (2014). Engagement through partnership: Students as partners in teaching and learning in higher education. York: Higher Education Academy.

Lizzio, A., \& Wilson, K. (2008). Feedback on assessment: Students' perceptions of quality and effectiveness. Assessment and Evaluation in Higher Education, 33(3), pp. 263-275. https://doi.org/10.1080/02602930701292548

McCulloch, A. (2009). The student as co-producer: Learning from public administration about the student-university relationship. Studies in Higher Education, 34(2), pp. 171-183. https://doi.org/10.1080/03075070802562857

Mercer-Mapstone, L., Dvorakova, S. L., Matthews, K. E., Abbot, S., Cheng, B., Felten, P., Knorr, K., Marquis, E., Shammas, R., \& Swaim, K. (2017). A systematic literature review of students as partners in higher education. International Journal for Students as Partners, 1(1), pp. 1-23. https://doi.org/10.15173/ijsap.v1i1.3119

Raftery, J. (2018). A university turnaround: Adaptive leadership at London Metropolitan University, 2014 to 2018. Higher Education Policy Institute Policy Note, 9. Retrieved from https://www.hepi.ac.uk/wp-content/uploads/2018/10/EMBARGOED-UNTIL-18OCT-2018-Policy-Note-9-A-University-Turnaround Screen.pdf

Ramsden, P. (2008). The future of higher education: Teaching and the student experience. York: Higher Education Academy.

Ratcliffe, A., \& Dimmock, A. (2013). What does student engagement mean to students? In E. Dunne \& D. Owen (Eds.), The student engagement handbook. Bingley: Emerald Group Publishing, pp. 59-75.

Thomas, L., (2012). Building student engagement and belonging in higher education at a time of change. London: Paul Hamlyn Foundation.

Tschirhart, C. (2017). The survey that is not a survey: engaging staff and students through meaningful feedback, presented at HEA Surveys Conference, Manchester, 2017.

Van der Velden, G. (2013). Staff perceptions of student engagement. In E. Dunne \& D. Owen (Eds.), The student engagement handbook. Bingley: Emerald Group Publishing, pp. 77-92. 